\title{
ESTRUTURA DA SINÚSIA EPIFÍTICA E EFEITO DE BORDA EM UMA ÁREA DE TRANSIÇÃO ENTRE FLORESTA ESTACIONAL SEMIDECÍDUA E FLORESTA OMBRÓFILA MISTA
}

\author{
Silvana Bernardi ${ }^{1}$, Jean Carlos Budke ${ }^{2}$ \\ ${ }^{1}$ Bióloga, Universidade Regional Integrada do Alto Uruguai e das Missões, URI, Erechim, RS, Brasil - silvana.bernardi@ yahoo.com.br \\ ${ }^{2}$ Biólogo, Dr., Depto. de Ciências Biológicas, Universidade Regional Integrada do Alto Uruguai e das Missões, URI, Erechim, RS, Brasil - \\ jean@uricer.edu.br
}

Recebido para publicação: 16/09/2008 - Aceito para publicação: 11/05/2009

\begin{abstract}
Resumo
Tendo em vista a baixa disponibilidade de informações sobre a sinúsia epifítica vascular na região Sul do Brasil, o objetivo deste trabalho foi descrever a estrutura de epífitos vasculares considerando o efeito de borda em uma área de transição entre Floresta Estacional Semidecídua e Floresta Ombrófila Mista. O levantamento foi realizado em um remanescente de 60 ha na região norte do Rio Grande do Sul. Foram analisados 499 forófitos, com perímetro a $1,3 \mathrm{~m}$ do solo $\geq 15 \mathrm{~cm}$, em 40 unidades amostrais de $10 \times 10 \mathrm{~m}$, sendo 20 localizadas em área de borda e 20 no interior do remanescente. Os forófitos foram divididos em cinco estratos, para análise da distribuição vertical das espécies, e suas estruturas comunitárias foram comparadas através de análise de agrupamento. Foram coletados dados referentes à luminosidade, umidade relativa do ar e temperatura para cada unidade amostral. As espécies com maior frequência e dominância foram Peperomia trineuroides Dahlst., para a área de borda, e Lepismium cruciforme (Vell.) Miquel para a área de interior. As estimativas de umidade, temperatura e luminosidade diferiram $(P<0,001)$ entre as áreas de borda e interior, enquanto que diversidade e equabilidade não foram estatisticamente diferentes. Embora não tenham ocorrido diferenças estruturais entre borda e interior, houve variação estrutural ao longo do gradiente vertical da floresta.

Palavras-chave: Estratificação vertical; forófito; luminosidade; remanescente florestal; Sul do Brasil.
\end{abstract}

\begin{abstract}
Structure of vascular epiphytes communities and the edge-effect relationships in a transitional area of seasonal semideciduous forest and rain mixed forest. Due to the low amount of information about the structure of epiphytes in southern Brazil the aim of this work was to describe the phytosociological structure of vascular epiphytes and edge-effect relationships in a transitional remnant between semideciduous seasonal forest and rain mixed forest. The survey was conducted in a 60 ha forest remnant located at northern Rio Grande do Sul state. We analyzed 499 host-trees with perimeter at breast height $\geq 15 \mathrm{~cm}$ distributed in 40 sampling units of $10 \times 10 \mathrm{~m} \mathrm{(20} \mathrm{at} \mathrm{the} \mathrm{edge} \mathrm{and} 20$ at inside the remnant). The host-trees were divided in five strata to analyze vertical distribution of epiphytes and their community structures were compared by cluster analysis. We also collected data from lightness, relative humidity and air temperature in each sampling unit. The most frequent and dominant species were Peperomia trineuroides Dahlst. at the edge and Lepismium cruciforme (Vell.) Miq. at the inside site. Diversity and equability at both sites were not statistically different, by other hand, light, relative humidity and air temperature were quite different $(P<0.001)$. There are not structural differences between edge and inside sites to the epiphyte community, although slight differences occurred across the vertical forest strata to epiphyte community.
\end{abstract}

Keywords: Forest remnant; host-trees; lightness; southern Brazil; vertical strata.

\section{INTRODUÇÃO}

Entre as alterações desencadeadas pelo homem na natureza e intensificadas no último século, a degradação de habitats pode ser considerada o principal processo que conduz à perda de espécies (HENLE et al., 1996). Em se tratando de florestas, quando a vegetação natural é interrompida por barreiras antrópicas, tais como estradas, povoados, pastagens, culturas agrícolas ou até mesmo por 
barreiras naturais, como montanhas, lagos e outras formações vegetais, capazes de diminuir significativamente o fluxo de animais, pólen ou sementes, forma-se, então, um fragmento florestal (VIANA, 1990).

As mudanças físicas associadas com a perda de habitats e fragmentação incluem: (1) a redução da área total e recursos dos habitats nativos; (2) incremento no isolamento dos fragmentos remanescentes e de suas populações locais; (3) alterações significativas nas características ambientais dos fragmentos, incluindo mudanças na radiação solar, ventos e umidade, que em conjunto compõem o efeito de borda (SAUNDERS et al., 1991).

A borda é a região dos limites de um elemento da paisagem onde as influências dos arredores impedem o desenvolvimento das condições ambientais interiores (FORMAN; GODRON, 1986). Esse fato interfere diretamente em comunidades de epífitos, já que a maioria das espécies epifíticas é específica de seu microambiente, devido suas características fisiológicas e nutricionais. A ocupação das epífitas nas árvores hospedeiras (forófitos) está relacionada a fatores abióticos, como luz, umidade, temperatura e substrato (FONTOURA, 2001).

As espécies epifíticas são típicas de florestas tropicais e úmidas, no entanto a abundância e a diversidade são fortemente influenciadas pela mudança de condições ecológicas ao longo de gradientes altitudinais, latitudinais e continentais (GENTRY; DODSON, 1987a;b). Temperaturas mais ou menos elevadas, associadas a precipitação intensa e regular, podem favorecer o desenvolvimento de comunidades epifíticas altamente diversificadas, cujas floras e estruturas comunitárias ainda são pouco conhecidas (WAECHTER, 1998). Regionalmente, a distribuição de chuvas ao longo do ano parece ser mais importante para o sucesso dos epífitos que o total anual de chuva na área (GENTRY; DODSON, 1987a).

Entre os efeitos de borda que decorrem da fragmentação de ambientes florestais, estão a proliferação de vegetação heliófita, a redução da umidade relativa e grandes variações na temperatura, o aumento do número de parasitas hematófagos e das taxas de predação (LAURANCE, 1999). Além disso, as mudanças microclimáticas e no regime de luz afetam a germinação e sobrevivência das espécies. $\mathrm{O}$ interior passa a ser bombardeado por uma chuva de sementes de plantas ruderais e há um aumento significativo nas taxas de queda de árvores e de mortalidade, alterando a composição e estrutura do remanescente, muitas vezes direcionando os fragmentos para estádios iniciais de sucessão (TABARELLI et al., 2008).

Outra questão importante é que a área de distribuição de cada espécie pode estar relacionada aos fatores físicos e biológicos do meio, bem como aos atributos ecológicos da própria espécie, os quais podem limitá-la a determinados locais. Uma forma de entender como os fatores ecológicos limitam a distribuição de uma espécie é a distinção através do nicho fundamental e do nicho percebido. As espécies são capazes de tolerar certa variação dos fatores físicos - temperatura, umidade - e podem, em teoria, viver em qualquer lugar dentro dos limites de tolerância. Entretanto cada espécie irá ocupar uma área menor do que poderia em função das interações multidimensionais com o meio (RIDLEY, 1996). Portanto, as epífitas têm um papel fundamental em estudos sobre interferência antrópica, por refletirem diretamente o grau de conservação local, uma vez que alguns grupos são menos tolerantes às variações ambientais decorrentes da devastação e de outros elementos (DE LA SOTA, 1971).

Além de todos esses fatores, a fragmentação florestal provoca a diminuição do número de indivíduos de determinadas populações, favorecendo a perda da variabilidade genética destas. A população remanescente passa a ter um tamanho menor que o mínimo, prejudicando sua continuidade e evolução. Nessa população pequena pode ocorrer, a curto prazo, deriva genética, o que significa ter a frequência de seus genes afastada daquelas da população original, inclusive chegando a perder alelos. Em longo prazo, ainda pode haver aumento da endogamia, decorrente da maior probabilidade de autofecundação e acasalamento entre indivíduos aparentados (KAGEYAMA et al., 1998).

É cada vez maior o interesse em relação às epífitas, devido à sua exploração econômica, enquanto fornecedoras de fármacos ou como plantas ornamentais, em razão da beleza singular de suas folhas e flores (LEME, 1993). Nesse sentido, o presente estudo busca investigar se: (1) há variação na estrutura e composição dos epífitos vasculares ao longo de um gradiente de borda interior de floresta, inserido em uma área de transição entre Floresta Estacional Semidecídua e Floresta Ombrófila Mista; (2) existe relação entre fatores físicos (luminosidade, temperatura e umidade) e a estrutura da sinúsia epifítica ao longo desse gradiente. 


\section{MATERIAL E MÉTODOS}

\section{Área de estudo}

O levantamento da sinúsia epifítica foi desenvolvido no Horto Florestal Municipal de Erechim, localizado próximo à rodovia RS-135. O município está inserido na região Alto Uruguai (ponto central nas coordenadas $27^{\circ} 37^{\prime} 54^{\prime \prime} \mathrm{S}$ e $52^{\circ} 16{ }^{\prime} 52^{\prime}$ 'W), possuindo uma área de $452,86 \mathrm{~km}^{2}$ e situando-se a $768 \mathrm{~m}$ acima do nível do mar. Historicamente, o clima da região foi descrito como Cfa, de acordo com a classificação climática de Köppen (NIMER, 1990). No entanto, dados referentes à Estação Meteorológica de Erechim, instalada a $750 \mathrm{~m}$ s.n.m., para o período de 1976 a 2005, apresentaram temperatura média anual de $17,6^{\circ} \mathrm{C}$, sendo a mínima registrada para o mês de junho $\left(12,7^{\circ} \mathrm{C}\right)$ e a máxima para o mês de janeiro $\left(25,5^{\circ} \mathrm{C}\right)$. As chuvas são bem distribuídas ao longo do ano e atingem precipitação média de 1912,3 mm.ano ${ }^{-1}$. Esses elementos associados caracterizam o clima da região, na verdade, como pertencendo ao tipo $\mathrm{Cfb}$ de Köppen.

O Horto Florestal é considerado uma unidade de proteção ambiental de categoria municipal, com área aproximada de 60 hectares. Caracteriza-se por incluir um fragmento de vegetação natural, numa transição entre Floresta Ombrófila Mista e Floresta Estacional Semidecídua, inserido em uma matriz predominantemente agrícola, tendo em sua área de influência indireta propriedades caracterizadas pela agricultura familiar.

\section{Levantamento do componente epifítico vascular e análise dos dados}

O levantamento de dados do componente epifítico vascular foi realizado entre os meses de novembro de 2007 e março de 2008. Para a realização do estudo, foram estabelecidas 40 unidades amostrais de 10 x $10 \mathrm{~m}$ cada, correspondendo a uma área de 0,4 ha. Destas, 20 localizaram-se na região da borda nordeste do fragmento, enquanto que as outras 20 unidades alocaram-se no interior da floresta.

Para a amostragem da sinúsia epifítica, foram considerados como forófitos todos os indivíduos arbóreos com perímetro à altura do peito $(\mathrm{PAP}) \geq 15 \mathrm{~cm}$. Cada um dos forófitos foi identificado no nível de espécie e teve sua altura total e perímetro mensurados.

Para o levantamento, os forófitos foram divididos em estratos com os seguintes intervalos de altura: 0 a $2 \mathrm{~m}, 2$ a $4 \mathrm{~m}, 4$ a $8 \mathrm{~m}, 8$ a $14 \mathrm{~m}$ e acima de $14 \mathrm{~m}$. Em cada um deles foram registradas todas as espécies epifíticas ocorrentes, através de escalada nos forófitos e também com o auxílio de binóculo. Os epífitos coletados foram herborizados, identificados e catalogados junto ao Herbário Padre Balduíno Rambo (HPBR) da Universidade Regional Integrada do Alto Uruguai e das Missões, campus de Erechim. As espécies foram agrupadas nas famílias reconhecidas pelo APG II (2003) e Smith et al. (2006), sendo que a nomenclatura das espécies foi organizada de acordo com a base de dados $\mathrm{W}^{3}$ Tropicos (TROPICOS, 2008) e Zuloaga et al. (2008). As abreviaturas dos nomes dos autores seguiram Brummitt; Powell (1992).

Os epífitos foram classificados, segundo sua relação com o forófito, em holoepífitos (verdadeiros, facultativos ou acidentais) e hemiepífitos (primários e secundários) (BENZIG, 1990). A cobertura de cada espécie em cada intervalo foi estimada visualmente utilizando-se a seguinte escala: 1 $(1 \%), 2(25 \%), 3(50 \%), 4(75 \%)$ e $5(100 \%)$. O valor de importância epifítico (VIE) foi calculado a partir da média dos valores de frequência e dominância relativos. Foi avaliada a diversidade das áreas através do índice de diversidade de Shannon ( $\left.\mathrm{H}^{\prime}\right)$ e da equabilidade de Pielou $\left(\mathrm{J}^{`}\right)$. A diferença entre os índices de diversidade de Shannon foi avaliada através do teste $t$ de Hutchinson (OLIVEIRA-FILHO et al., 2004).

No levantamento das variáveis abióticas, foram coletados dados relativos à temperatura e umidade relativa do ar, com o auxílio de Psicrômetro Digital Amprobe, e incidência de luz, utilizando um luxímetro digital Minipa. Para as estimativas das variáveis, foram realizadas cinco mensurações em cada unidade amostral, sendo uma localizada no centro e as demais nos vértices. As medidas foram obtidas a aproximadamente um metro e meio de altura do solo. Os dados foram coletados partindo-se das unidades amostrais de borda e seguindo para o interior, de forma rápida, para se evitar alterações oriundas do momento de coleta (ex.: inclinação do sol).

Foram aplicados testes de correlação (Spearman), buscando-se relações entre a estrutura da sinúsia epifítica e variáveis ambientais para a área de borda e para o interior da floresta, bem como relacionar as possíveis variações em função da distância da borda. Para as análises estatísticas, foi utilizado o programa Palentological Statistics - PAST 1.81 (HAMMER et al., 2008). 
A similaridade estrutural entre os estratos foi realizada através do índice de similaridade de Jaccard, pelo qual são investigadas as espécies que ocorrem em conjunto e as espécies exclusivas de cada estrato, sempre analisadas duas a duas (MUELLER-DOMBOIS; ELLENBERG, 1974). Para uma visualização das distâncias entre estratos (unidades amostrais), foi utilizada uma análise de agrupamento, empregando-se a técnica de UPGMA (média ponderada), como forma de ligação entre unidades amostrais (ZAR, 1996). As unidades amostrais de borda e interior foram classificadas através de análise de agrupamento pelo método de variância mínima, a qual utiliza a distância euclidiana como medida de similaridade. A significância dos agrupamentos, em ambas as análises, foi testada por meio de autorreamostragem bootstrap (PILLAR, 1999) ao nível de significância de $\alpha<0,05$, através do programa MULTIV (PILLAR, 2006).

\section{RESULTADOS}

No levantamento dos indivíduos epifíticos vasculares, foram identificadas 22 espécies, pertencentes a oito famílias. Polypodiaceae (seis espécies) seguida por Cactaceae e Orchidaceae (quatro espécies cada) foram as famílias com maior riqueza, tanto na borda quanto no interior do fragmento. Por sua vez, Bromeliaceae e Piperaceae apresentaram duas espécies, e Commelinaceae, Aspleniaceae e Gesneriaceae apresentaram uma única espécie.

Tabela 1. Parâmetros estruturais das espécies epifíticas amostradas em área de borda, Horto Municipal de Erechim, RS. FA: frequência absoluta (\%); FR: frequência relativa; DoA: dominância absoluta; DoR: dominância relativa; VIE: valor de importância epifítico.

Table 1. Structural parameters from epiphytes at the remnant edge, Horto Municipal de Erechim, RS FA: absolute frequency (\%); FR: relative frequency; DoA: absolute dominance; DoR: relative dominance; VIE: epiphytic importance value.

\begin{tabular}{lcccccc}
\hline Espécie & Família & FA & FR & DoA & DoR & VIE \\
\hline Peperomia trineuroides Dahlst. & Piperaceae & 70 & 12,6 & 150 & 28 & 20,5 \\
Microgramma squamulosa (Kaulf.) de la Sota & Polypodiaceae & 60 & 10,8 & 101 & 19 & 14,9 \\
Lepismium cruciforme (Vell.) Miq. & Cactaceae & 65 & 11,7 & 83 & 16 & 13,7 \\
Peperomia delicatula Henschen & Piperaceae & 75 & 13,5 & 35 & 6,6 & 10,0 \\
Bilbergia nutans Wendl. & Bromeliaceae & 35 & 6,3 & 42 & 8 & 7,1 \\
Lepismium houlletianum (Lem.) Barthott & Cactaceae & 45 & 8,1 & 19 & 3,6 & 5,8 \\
Lepismium lumbricoides (Lem.) Barthlott & Cactaceae & 30 & 5,4 & 21 & 4 & 4,6 \\
Tillandsia tenuifolia L. & Bromeliaceae & 25 & 4,5 & 5 & 0,9 & 2,7 \\
Commelina sp. & Commelinaceae & 15 & 2,7 & 13 & 2,5 & 2,5 \\
Sinningia douglasii (Lindl.) Chautems & Gesneriaceae & 20 & 3,6 & 8 & 1,5 & 2,5 \\
Campyloneurum nitidum (Kaulf.) C. Presl & Polypodiaceae & 15 & 2,7 & 12 & 2,3 & 2,4 \\
Pleopeltis pleopeltifolia (Raddi) Alston & Polypodiaceae & 15 & 2,7 & 8 & 1,5 & 2,1 \\
Pleurothallis sonderana Rchb. f. & Orchidaceae & 15 & 2,7 & 3 & 0,6 & 1,6 \\
Rhipsalis floccosa Salm-Dyck ex Pfeiff. & Cactaceae & 10 & 1,8 & 8 & 1,5 & 1,6 \\
Pleopeltis squalida (Vell.) de la Sota & Polypodiaceae & 15 & 2,7 & 3 & 0,6 & 1,6 \\
Pleopeltis hirsutissima (Raddi) de La Sota & Polypodiaceae & 10 & 1,8 & 6 & 1,1 & 1,4 \\
Pleurothalis cf. petropolitana Hoehne & Orchidaceae & 10 & 1,8 & 3 & 0,6 & 1,1 \\
Pecluma truncorum (Lindm.) M.G. Price & Polypodiaceae & 10 & 1,8 & 2 & 0,4 & 1,0 \\
Bulbophyllum regnelli Rchb. f. & Orchidaceae & 5 & 0,9 & 3 & 0,6 & 0,7 \\
Asplenium sp. & Aspleniaceae & 5 & 0,9 & 2 & 0,4 & 0,6 \\
Oncidium widgrenii Lind. & Orchidaceae & 5 & 0,9 & 1 & 0,2 & 0,5 \\
\hline
\end{tabular}

Os parâmetros fitossociológicos calculados para as espécies epifíticas amostradas na borda encontram-se na tabela 1. A espécie com o maior VIE foi Peperomia trineuroides, devido aos valores elevados de dominância e frequência relativas, seguida por Microgramma squamulosa, polipodiácea bem representada no sub-bosque e que, embora possua frequência intermediária, apresenta uma dominância elevada. Por outro lado, Lepismium cruciforme apresentou dominância e frequência intermediárias, ficando bem representada na sinúsia epifítica. As demais espécies apresentaram estimativas decrescentes, 
sendo que muitas delas, especialmente de Orchidaceae, apresentaram baixa frequência e dominância, sendo consideradas pouco comuns na área de borda.

Foram amostrados um número total de 499 forófitos, sendo 228 amostrados na borda e 271 no interior. O número médio de indivíduos por unidade amostral foi de 11,4 (1.140 ind.ha $\left.{ }^{-1}\right)$, enquanto que em área de interior a média foi de 13,5 (1.350 ind.ha $\left.{ }^{-1}\right)$, não havendo diferença significativa entre os valores médios. Concomitante a isso, a área basal dos forófitos também não variou, pois, apesar de algumas unidades amostrais possuírem maior número de indivíduos, principalmente em região de interior, estes eram representados por árvores de pequeno porte, portanto a biomassa de cada forófito era menor, enquanto que as unidades amostrais com menor número de indivíduos, na maioria em área de borda, apresentavam árvores com maior porte. Dessa forma, ocorreu um equilíbrio entre as duas áreas, sendo no interior a área basal média de 7,43 $\mathrm{m}^{2}$.ha ${ }^{-1}$ e na borda $5,48 \mathrm{~m}^{2}$. ha ${ }^{-1}$, sem diferenças significativas $(P=0,157)$.

No interior do fragmento (Tabela 2), as espécies com maior valor epifítico foram Lepismium cruciforme, Peperomia trineuroides e Peperomia delicatula, com valores de importância bem acima das demais espécies. Destacam-se as espécies do gênero Peperomia, muito comuns nessa área (Tabela 2). Da mesma forma que na borda, a família Orchidaceae apresentou baixa frequência e dominância, com espécies de ocorrência restrita. Microgramma squamulosa, por outro lado, espécie que apresentou elevada dominância na área de borda, foi relativamente pouco abundante no interior.

Tabela 2. Parâmetros estruturais das espécies epifíticas amostradas em área de interior, Horto Municipal de Erechim, RS. FA: frequência absoluta (\%); FR: frequência relativa; DoA: dominância absoluta; DoR: dominância relativa; VIE: valor de importância epifítico.

Table 2. Structural parameters from vascular epiphytes at inside site from Horto Municipal de Erechim, RS. FA: absolute frequency (\%); FR: relative frequency; DoA: absolute dominance; DoR: relative dominance; VIE: epiphytic importance value.

\begin{tabular}{lcccccc}
\hline Espécie & Família & FA & FR & DoA & DoR & VIE \\
\hline Lepismium cruciforme (Vell.) Miq. & Cactaceae & 95 & 12,9 & 229 & 24,1 & 18,5 \\
Peperomia trineuroides Dahlst. & Piperaceae & 90 & 12,2 & 211 & 22,2 & 17,2 \\
Peperomia delicatula Henschen & Piperaceae & 95 & 12,9 & 129 & 13,6 & 13,2 \\
Bilbergia nutans Wendl. & Bromeliaceae & 70 & 9,5 & 97 & 10,2 & 9,8 \\
Lepismium houlletianum (Lem.) Barthlott & Cactaceae & 70 & 9,5 & 71 & 7,4 & 8,5 \\
Microgramma squamulosa (Kaulf.) de la Sota & Polypodiaceae & 55 & 7,4 & 48 & 5,0 & 6,2 \\
Lepismium lumbricoides (Lem.) Barthlott & Cactaceae & 55 & 7,4 & 28 & 2,9 & 5,2 \\
Pleopeltis squalida (Vell.) de la Sota & Polypodiaceae & 35 & 4,7 & 27 & 2,8 & 3,8 \\
Campyloneurum nitidum (Kaulf.) C. Presl & Polypodiaceae & 40 & 5,4 & 16 & 1,6 & 3,5 \\
Tillandsia tenuifolia L. & Bromeliaceae & 20 & 2,7 & 15 & 1,5 & 2,1 \\
Sinningia douglasii (Lindl.) Chautems & Gesneriaceae & 15 & 2,0 & 8 & 0,8 & 1,4 \\
Pleopeltis hirsutissima (Raddi) de La Sota & Polypodiaceae & 10 & 1,3 & 9 & 0,9 & 1,1 \\
Oncidium widgrenii Lind. & Orchidaceae & 10 & 1,3 & 4 & 0,4 & 0,8 \\
Bulbophyllum regnelli Rchb.f. & Orchidaceae & 5 & 0,6 & 2 & 0,2 & 0,4 \\
Rhipsalis floccosa Salm-Dyck ex Pfeiff. & Cactaceae & 5 & 0,6 & 1 & 0,1 & 0,3 \\
Pecluma truncorum (Lindm.) M.G. Price & Polypodiaceae & 5 & 0,6 & 1 & 0,1 & 0,3 \\
Pleurothalis cf. petropolitana Hoehne & Orchidaceae & 5 & 0,6 & 1 & 0,1 & 0,3 \\
Pleopeltis pleopeltifolia (Raddi) Alston & Polypodiaceae & 5 & 0,6 & 1 & 0,1 & 0,3 \\
\hline
\end{tabular}

O índice de diversidade de Shannon e equabilidade de Pielou foram, para a borda, respectivamente 2,38 e 0,78 , com riqueza de 20 espécies. No interior do remanescente, a riqueza foi a mesma e a diversidade de Shannon foi de 2,27, com equabilidade de 0,75. Os valores de equabilidade, que avalia a participação proporcional das espécies presentes, foram baixos quando comparados a outras comunidades epifíticas no Sul do país (Tabela 3). A equabilidade mais elevada foi registrada nas matas brejosas do Taim, enquanto a mais baixa foi encontrada em um trecho de Floresta Ombrófila Mista Aluvial no Paraná (KERSTEN; SILVA, 2002). A diversidade não variou de forma significativa entre o interior e a borda do fragmento $(P=0,09)$, porém houve tendência de aumento nas áreas de borda. 
Tabela 3. Riqueza e diversidade de epífitos vasculares em diversos estudos realizados no Sul do Brasil. Nf: número de forófitos amostrados; Sf: número de famílias epífiticas; Se: número de espécies epifíticas; H': índice de Shanonn; J: índice de equabilidade de Pielou.

Table 3. Richness and diversity of vascular epiphytes in Southern Brazil. Nf: number of tree-hosts sampled; Sf: number of epiphytic families; Se: number of epiphytic species; H': Shannon index; J: Pielou index.

\begin{tabular}{lcccccc}
\hline Estudos & Local & Nf & Sf & Se & H' & J \\
\hline Giongo; Waechter, 2004 & Eldorado do Sul-RS & 60 & 13 & 50 & 3,434 & 0,87 \\
Kersten; Silva, 2001 & Ilha do Mel-PR & 100 & 17 & 77 & 3,609 & 0,78 \\
Kersten; Silva, 2002 & Araucária-PR & 110 & 12 & 51 & 2,706 & 0,76 \\
Presente estudo & Erechim-RS/borda & 228 & 7 & 20 & 2,380 & 0,78 \\
Presente estudo & Erechim-RS/interior & 271 & 8 & 21 & 2,271 & 0,75 \\
Waechter, 1992 & Faxinal/Laguneiro-Torres-RS & 60 & 14 & 93 & 4,049 & 0,89 \\
Waechter, 1992 & Taim-Rio Grande-RS & 60 & 8 & 24 & 2,886 & 0,91 \\
Waechter, 1998 & Emboaba-Osório-RS & 60 & 12 & 53 & 2,990 & 0,87 \\
\hline
\end{tabular}

Não ocorreram diferenças significativas entre os valores de diversidade ao longo dos estratos da borda, variando entre 1,89 nats.ind ${ }^{-1}$ e 2,27 nats.ind ${ }^{-1}$ (Tabela 4). Por outro lado, no interior do fragmento, os intervalos de 0 a $2 \mathrm{~m}$ e acima de $14 \mathrm{~m}$ apresentaram diversidade significativamente menor que as áreas intermediárias. A riqueza de espécies na borda variou de 10 a 18 espécies por estrato, valores aproximados daqueles verificados no interior (Tabela 5).

Tabela 4. Riqueza específica, diversidade de Shannon e equabilidade de Pielou para diferentes intervalos de altura ao longo da borda do fragmento. A diferença entre os valores de diversidade não foi significativa para testes $\mathrm{t}(\mathrm{P}<0,05)$.

Table 4. Richness, Shannon`s diversity index and Pielou`s equability of different height intervals at the remnant edge. Differences among diversity values were not significant for t-tests $(\mathrm{P}<0.05)$.

\begin{tabular}{lccccc}
\hline Parâmetro & $\mathbf{0 - 2}$ & $\mathbf{2 - 4}$ & $\mathbf{4 - 8}$ & $\mathbf{8 - 1 4}$ & $\geq \mathbf{1 4}$ \\
\hline Riqueza & 13 & 13 & 18 & 16 & 10 \\
Diversidade (H') & $2,12 \mathrm{a}$ & $2,11 \mathrm{a}$ & $2,27 \mathrm{a}$ & $2,25 \mathrm{a}$ & $1,89 \mathrm{a}$ \\
Equabilidade & 0,82 & 0,82 & 0,78 & 0,81 & 0,82 \\
\hline
\end{tabular}

Tabela 5. Riqueza específica, diversidade de Shannon e equabilidade de Pielou para diferentes alturas ao longo do interior do fragmento. Valores seguidos de letras diferentes diferem significativamente em testes $\mathrm{t}(\mathrm{P}<0,05)$.

Table 5. Richness, Shannon`s diversity index and Pielou`s equability of different height intervals at the inside site. Values followed by different letters are statistically different for t-tests $(\mathrm{P}<0.05)$.

\begin{tabular}{lccccc}
\hline Parâmetro & $\mathbf{0 - 2}$ & $\mathbf{2 - 4}$ & $\mathbf{4 - 8}$ & $\mathbf{8 - 1 4}$ & $\geq \mathbf{1 4}$ \\
\hline Riqueza & 12 & 13 & 15 & 18 & 11 \\
Diversidade (H') & $1,8 \mathrm{a}$ & $2,15 \mathrm{~b}$ & $2,04 \mathrm{~b}$ & $2,15 \mathrm{~b}$ & $1,84 \mathrm{a}$ \\
Equabilidade & 0,72 & 0,83 & 0,75 & 0,74 & 0,76 \\
\hline
\end{tabular}

Segundo a relação com o forófito, a maioria das espécies foi classificada como holoepífitas verdadeiras, exceto Comellina sp. (acidental) e Asplenium sp. (facultativa).

As comparações estatísticas analisadas entre borda e interior para as variáveis abióticas indicam que a luminosidade recebida em área de borda é consideravelmente maior do que em regiões de interior $(P<0,001)$, onde a média de luminosidade recebida foi de 176 lux, enquanto que em região de borda foi 389 lux. O mesmo ocorre com a umidade relativa do ar, que no interior do fragmento possui uma média de $71,5 \%$, enquanto que na borda esse número decresce para $52 \%(P<0,001)$. A temperatura variou significativamente entre a área de borda e interior $(P<0,001)$, sendo que em área de borda a temperatura média foi de $13,4^{\circ} \mathrm{C}$, enquanto que no interior essa temperatura atingiu a média de $11,9^{\circ} \mathrm{C}$.

De acordo com a figura 1 , observou-se que a distribuição das espécies da sinúsia epifítica variou de acordo com a elevação dos estratos, ou seja, intervalos em menores alturas demonstraram maior similaridade em termos de dominância relativa, independentemente da localização em borda ou interior 
da floresta. Essa similaridade diminui à medida que a altura dos estratos é maior. Da mesma forma, a distribuição das espécies foi restrita quanto à altura, com muitas espécies ocorrendo apenas nos intervalos mais baixos, enquanto que outras foram restritas aos estratos mais elevados. A análise de similaridade entre áreas de borda e interior (Figura 2) gerou três grupos nítidos, os quais apresentaram tanto unidades amostrais de interior quanto de borda dentro de cada grupo, refutando nossa hipótese inicial para a existência de estruturas distintas para comunidades de epífitos de borda e interior e indicando que muitas das espécies apresentam ampla distribuição na área, independentemente da distância da borda.

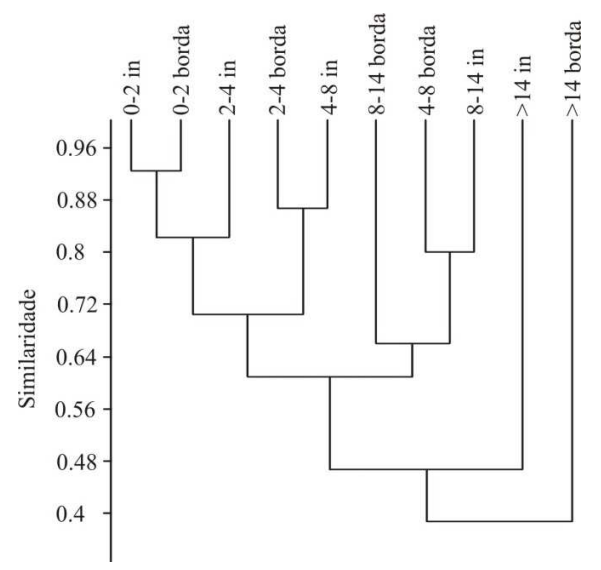

Figura 1. Similaridade florística (Jaccard) entre intervalos verticais em áreas de borda e interior em um remanescente de transição entre Floresta Estacional Semidecídua e Floresta Ombrófila Mista no Sul do Brasil. in: interior do fragmento; borda: borda do fragmento.

Figure 1. Similarity (Jaccard) among vertical intervals on the edge and inside a remnant transitional to seasonal semideciduous forest and rain mixed forest in Southern Brazil. in: inside site; edge: remnant edge.

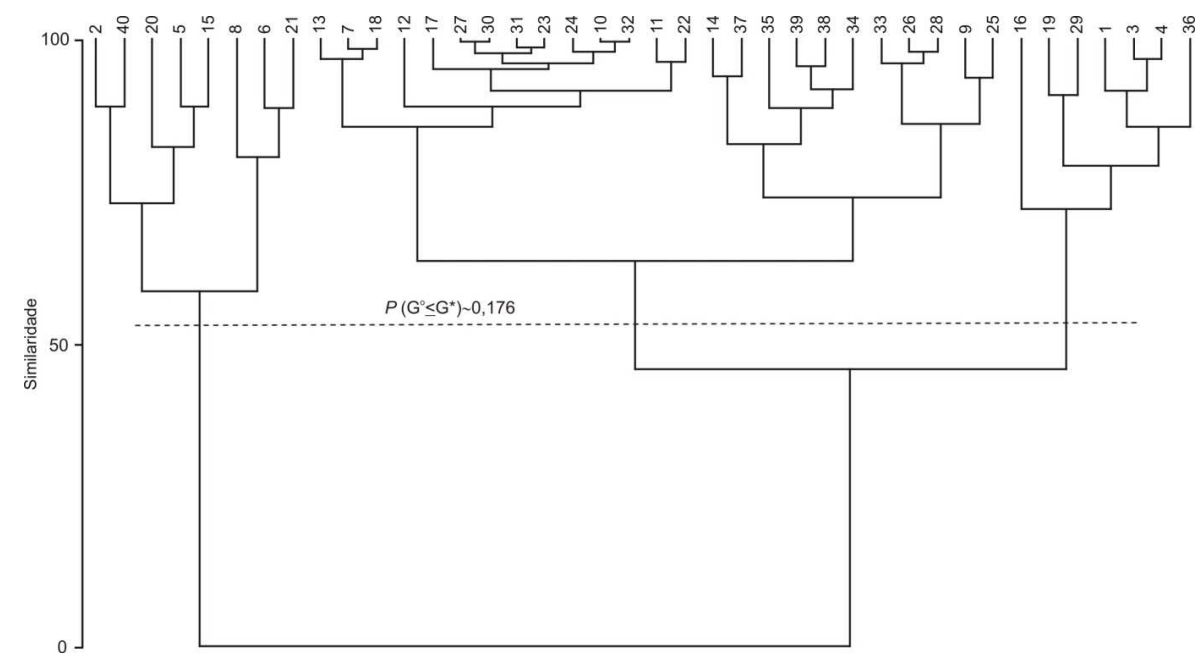

Figura 2. Similaridade estrutural (dominância absoluta) entre áreas de borda e interior em um remanescente de transição entre Floresta Estacional Semidecídua e Floresta Ombrófila Mista no Sul do Brasil. Unidades amostrais divididas de 1 a 20 (interior) e 21 a 40 (borda).

Figure 2. Structural similarity (absolute dominance) among edge and inside areas in a transitional remnant between seasonal semideciduous forest and rain mixed forest in Southern Brazil. Sampling units were divided from 1 to 20 (inside) and from 21 to 40 (edge). 


\section{DISCUSSÃO}

As cinco famílias mais ricas na flora epifítica estudada coincidem com algumas daquelas que normalmente se destacam nos levantamentos realizados no neotrópico (VALDIVIA, 1977; WAECHTER, 1986, 1998; STEEGE; CORNELISSEN, 1989; CATLING; LEFKOVITCH, 1989; ZIMMERMAN; OLMSTED, 1992).

Por outro lado, Gesneriaceae e Araceae, famílias relevantes para a flora epifítica neotropical, mas que apresentam distribuição de seus taxa epifíticos mais restrita às zonas tropicais (GENTRY; DODSON, 1987b; WAECHTER, 1998), foram pouco expressivas ou ausentes (Araceae) no levantamento.

Os índices de diversidade de Shannon e equabilidade de Pielou, como mostra a tabela 3, foram baixos em relação a trabalhos em outras comunidades epifíticas no sul do Brasil. Pode-se perceber que todas as áreas mais ricas e diversas situam-se ao norte, recebendo maior influência de elementos tropicais, enquanto que as de menor diversidade encontram-se no sul da Planície Costeira do Rio Grande do Sul (GIONGO; WAECHTER, 2004). Da mesma forma, o presente estudo revela índices de riqueza e de diversidade abaixo do registrado em região distante das influências tropicais, entretanto é próximo daquele encontrado para uma área de Floresta Ombrófila Mista no Primeiro Planalto Paranaense (KERSTEN; SILVA, 2002). Quanto à relação ecológica com o forófito, nos diversos trabalhos realizados em diferentes locais do Sul do Brasil, observou-se a dominância de holoepífitos verdadeiros sobre outras formas de vida, a exemplo do que foi encontrado em florestas da planície costeira paranaense (KERSTEN; SILVA, 2001), sul-rio-grandense (WAECHTER, 1998) e em Floresta Ombrófila Mista (Aluvial - KERSTEN; SILVA, 2002; Montana e Aluvial - BORGO; SILVA, 2003).

Os índices de riqueza e diversidade de espécies podem ser considerados baixos quando comparados a outros trabalhos no Sul do Brasil (WAECHTER, 1992; KERSTEN; SILVA, 2001; WAECHTER, 1998; WAECHTER, 1992; KERSTEN; SILVA, 2002; GIONGO; WAECHTER, 2004), condizendo aos padrões obtidos por Aguiar et al. (1981), Waechter (1992) e Piliackas et al. (2000), que identificaram, respectivamente, 17, 24 e 26 espécies, sendo esses valores bem próximos ao obtido neste trabalho.

Essa baixa riqueza observada pode ser atribuída ao fato de o remanescente estudado situar-se em uma região de transição entre Floresta Ombrófila Mista, normalmente apresentando grande riqueza, e Floresta Estacional Semidecídua, que segue os padrões opostos. Da mesma forma, a área em questão está próximo do limite sul da Floresta Ombrófila Mista e numa região de mudança de padrões climáticos, de áreas tropicais para subtropicais (WAECHTER, 1996).

Através dos resultados obtidos, é possível realizar uma primeira aproximação de que a comunidade epifítica dessa área reflete melhor as características de Floresta Estacional Semidecídua do que de Floresta Ombrófila Mista. Além disso, as espécies encontradas são de distribuição geográfica ampla, ocorrendo em grande parte do Sul do Brasil, como pôde ser observado nos levantamentos feitos por Kersten; Silva (2002) e Gonçalves; Waechter (2003), não havendo, portanto, endemismo ou espécies peculiares, ao contrário do que foi encontrado por Rogalski; Zanin (2003) no Estreito Augusto César, situado em um trecho de Floresta Estacional Decídua às margens do Rio Uruguai, Sul do Brasil. Entretanto, a baixa riqueza encontrada na área pode também estar associada ao processo de fragmentação da área, que pode ter diminuído a riqueza total da área ao longo do tempo. Observou-se que a temperatura e a luminosidade diminuem no gradiente bordainterior, enquanto que a umidade relativa do ar segue o padrão inverso.

Segundo Teixeira (1998), à medida que se adentra no fragmento, esses componentes abióticos passam a adquirir características intrínsecas do remanescente. A alta luminosidade existente em região de borda pode ser atribuída à grande interferência luminosa recebida da parte externa do fragmento, associada ao menor número de forófitos (mesmo estes possuindo uma maior área basal). O menor agrupamento faz com que as copas não se toquem, permitindo uma maior penetração de luminosidade. As mudanças na parte física do ambiente causadas pela borda podem afetar diretamente a estrutura da floresta (TEIXEIRA, 1998), podendo influenciar na distribuição de espécies epifíticas.

Apesar da disponibilidade de luz poder influenciar a distribuição de cada espécie epifítica, bem como a temperatura e a umidade do ar, esse padrão não foi observado neste estudo, sendo que a sinúsia epifítica não respondeu substancialmente a esses fatores. Isso pode ser explicado pelo fato de que as 
espécies encontradas são comuns tanto na borda quanto no interior, variando apenas sua dominância. Isso contradiz os resultados observados por Bataghin (2005) e Viero Dias (2006), os quais relataram distintas variáveis abióticas como preditoras da ocorrência de espécies epifíticas através do gradiente de borda e de interior em remanescentes de Floresta Ombrófila Mista. Embora ocorram tais variações entre a borda e o interior do remanescente, as estruturas e floras epifíticas não diferem significativamente, haja vista que as espécies com maior frequência e dominância em ambas as áreas são as mesmas.

Em relação à distribuição vertical nos forófitos, que também está intimamente ligada às relações hídricas e de luz, principalmente em comunidades vegetais fechadas, como as florestas tropicais, onde se forma um gradiente microclimático da superfície do solo para o topo das árvores (RICHARDS, 1952), a sinúsia epifítica variou significativamente entre os diferentes intervalos de altura, tanto em região de borda como de interior, onde os intervalos intermediários demonstram maior riqueza de espécies, ocorrendo o oposto no estrato de maior altura. Da mesma forma, a similaridade obtida através de análise de agrupamento é consideravelmente maior em estratos mais próximos ao solo, independentemente da localização do forófito - borda ou interior. À medida que a altura dos estratos fica maior, essa similaridade vai diminuindo. Isso indica que as espécies existentes em áreas mais baixas, tanto em área de borda quanto de interior, refletem maior similaridade do que entre os intervalos que se encontram em alturas maiores. Esse fato pôde ser observado nos estudos de Bataghin (2005), que verificou uma maior riqueza de espécies nos estratos inferiores dos forófitos.

A distribuição diferencial de espécies ao longo do gradiente vertical da floresta pode estar ocorrendo devido à maior temperatura e velocidade do vento nas partes superiores dos forófitos, fazendo com que diminua a umidade, fator extremamente necessário para o desenvolvimento de indivíduos epifíticos. Benzing (1990) atribui a ocorrência de poucas espécies nos ramos externos pelo fato de estes ramos serem muito recentes e dificultarem a instalação de algumas espécies por questões mecânicas e espaciais. No presente estudo, a baixa área basal e o elevado número de indivíduos arbóreos por área podem estar associados à elevada densidade de representantes de espécies ciófilas no sub-bosque (ZANARDI, 2008), fornecendo condições específicas ao estabelecimento de novas espécies epifíticas.

\section{CONCLUSÕES}

- Apesar das variações microclimáticas observadas em relação à temperatura, umidade e luminosidade nas unidades amostrais de borda e de interior, a sinúsia epifítica, mesmo muito sensível ao microclima, não respondeu significativamente à variação dos componentes abióticos, havendo a formação de grupos constituídos tanto por unidades amostrais de interior quanto de borda.

- A baixa riqueza de espécies encontrada na área, quando comparada a outros estudos no Sul do Brasil, indica que a sinúsia epifítica reflete as características de Floresta Estacional Semidecídua mais do que de Floresta Ombrófila Mista, apesar de o remanescente estar situado em uma área de transição. Por outro lado, o processo de fragmentação ocorrido na área pode ter contribuído na perda de espécies ao longo do tempo, devido ao processo de insularização.

- Quanto à variação estrutural do componente epifítico em relação à distribuição vertical sobre os forófitos, admite-se que a maior dominância nas áreas mais próximas ao solo, independentemente de estarem em área de borda ou interior e apesar da verticalidade do substrato, pode refletir o maior tempo de vida do forófito, além de características arquitetônicas, as quais permitem maior exposição ao desenvolvimento de indivíduos epifíticos.

\section{REFERÊNCIAS}

AGUiAR, L. W.; CITADINE-ZANETTE, V.; MARTAU, L.; BACKES, A. Composição florística de epífitos vasculares numa área localizada no município de Montenegro e Triunfo, Rio Grande do Sul, Brasil. Iheringia Série Botânica, Porto Alegre, v. 28, p. 55-93, 1981.

APG II. An update of the Angiosperm Phylogeny Group classification for the orders and families of flowering plants. Botanical Journal of the Linnean Society, London, v. 141, p. 399-436, 2003.

BATAGHIN, F. A. Estudo do efeito de borda sobre o componente epifítico em um fragmento de Floresta Ombrófila Mista. Monografia (Conclusão de Curso) - Universidade Regional Integrada do Alto Uruguai e das Missões, Erechim, 2005. 
BENZING, D. H. Vascular epiphytes - general biology and related biota. Cambridge: Cambridge University Press. 1990.

BORGO, M.; SILVA, S. M. Epífitos vasculares em fragmento de Floresta Ombrófila Mista, Curitiba, Paraná, Brasil. Revista Brasileira de Botânica, São Paulo, v. 26, p. 391-401, 2003.

CATLING, P. M.; LEFKOVITCH, L. P. Associations of vascular epiphytes in a Guatemalan cloud forest. Biotropica, Washington, v. 21, p. 35-40, 1989.

BRUMMITT, R. K.; POWELL, C. E. Authors of plant names. Kew: Royal Botanic Gardens, Kew. 1992.

DE LA SOTA, E. R. El epifitismo y las pteridofitas en Costa Rica (America Central). Nova Hedwigia, Stuttgart, v. 21, p. 401-465, 1971.

FONTOURA, T. Bromeliaceae e outras epífitas - estratificação e recursos disponíveis para animais na Reserva Ecológica Estadual de Jacarepiá, Rio de Janeiro. Bromélia, Rio de Janeiro, n. 6, p. 33-39, 2001.

FORMAN, R. T. T.; GODRON, M. Landscape Ecology. New York: J. Wiley \& Sons, 1986.

GENTRY, A. H.; DODSON, C. H. Diversity and biogeography of neotropical vascular epiphytes. Annals of the Missouri Garden, Saint Louis, v. 74, p. 205-233, 1987a.

GENTRY, A. H.; DODSON, C. H. Contribution of nontrees species richness of a tropical rain forest. Biotropica, Washington, v. 19, p. 149-156, 1987b.

GIONGO, C.; WAECHTER, J. L. Composição florística e estrutura comunitária de epífitos vasculares em uma floresta de galeria na Depressão Central do Rio Grande do Sul. Revista Brasileira de Botânica, São Paulo, v. 27, p. 563-572, 2004.

GONÇALVES, C. N.; WAECHTER, J. L. Aspectos Florísticos de Epífitos Vasculares Sobre Figueiras Isoladas no Norte da Planície Costeira do Rio Grande do Sul. Acta Botanica Brasilica, São Paulo, v. 17, p. 98-100, 2003.

HAMMER, Ø.; HARPER, D. A. T.; RYAN, P. D. PAST: Paleontological Statistics software package for education and data analysis 1.81. Disponível em: <http://folk. uio.no/o hammer/past> Acesso em: 15/07/2008.]

HENLE, K.; POSCHLOD, P.; MARGULES, C.; SETTELE, J. Species survival in relation to habitat quality, size and isolation: summary conclusions and future directions. In: SETTELE J.; MARGULES C.; POSCHLOD, P. Species survival in fragmented landscapes. Dordrecht: Kluwer Academic, 1996. p. 363-371.

KAGEYAMA, P. Y; GANDARA, F. B.; SOUZA, L. M. I. Conseqüências Genéticas da Fragmentação sobre Populações de Espécies Arbóreas. Série técnica IPEF, Piracicaba, v. 12, p. 65-70, 1998.

KERSTEN, R. A.; SILVA, S. M. Composição florística e estrutura do componente epifítico vascular em floresta da planície litorânea na Ilha do Mel, Paraná, Brasil. Revista Brasileira de Botânica, São Paulo, v. 24, p. 213-226, 2001.

KERSTEN, R. A.; SILVA, S. M. Florística e estrutura do componente epifítico vascular em Floresta Ombrófila Mista aluvial do Rio Barigüi, Paraná, Brasil. Revista Brasileira de Botânica, São Paulo, v. 25, p. 259-267, 2002.

LAURANCE, W. F. Gaia's lungs: are the rainforests inhaling earth's excess carbon dioxide? Natural History, New York, v. 108, p. 96, 1999.

LEME, E. M. C. Bromélias na Natureza. Rio de Janeiro: Marigo Comunicação Visual. 1993.

MULLER DOMBOIS, D.; ELLENBERG, H. Aims and methods of vegetation ecology. New York: J. Wiley. 1974.

NIMER, E. Clima. In: IBGE. Fundação Instituto Brasileiro de Geografia e Estatística. Geografia do Brasil: região sul. Rio de Janeiro: IBGE, 1990. p. 151-187. 
OLIVEIRA-FILHO, A. T.; CARVALHO, D. A.; VILELA, E. A.; CURI, N.; FONTES, M. A. L. Diversity and structure of the tree community of a fragment of tropical secondary forest of the Brazilian Atlantic Forest domain 15 and 40 years after logging. Revista Brasileira de Botânica, São Paulo, v. 27, p. 685-701, 2004.

PILIACKAS, J. M.; BARBOSA, L. M.; CATHARINO, E. L. M. Levantamento das epífitas vasculares do Rio Picinguaba. Ubatuba, São Paulo. In: SIMPÓSIO DE ECOSSISTEMAS BRASILEIROS, 5., 2000, Vitória. Anais... São Paulo: Aciesp, 2000. p. 357-363.

PILLAR, V. P. How sharp are classifications? Ecology, New York, v. 80, p. 2508-2516, 1999.

PILLAR, V. D. Multivariate exploratory analysis, randomization testing and bootstrap resampling MULTIV, versão 2.3.20. Porto Alegre: UFRGS .Departamento de Ecologia, 2006.

RICHARDS, P. W. The Tropical Rain Forest - An Ecological Study. Cambridge: Cambridge University Press, 1952.

RIDLEY, M. Evolution. Malden: Blackwell Science, 1996.

ROGALSKI, J. M.; ZANIN, E. M. Composição florística de epífitos vasculares no estreito de Augusto César, Floresta Estacional Decidual do Rio Uruguai, RS, Brasil. Revista Brasileira de Botânica, São Paulo, v. 26, p. 551-556, 2003.

SAUNDERS D. A.; HOBBS R. J.; MARGULES C. R Biological consequences of ecosystem fragmentation: A review. Conservation Biology, Malden, v. 5, p. 18-32, 1991.

SMITH, A. R.; PRYER, K. M.; SCHUETTPELZ, E.; KORALL, P.; SCHNEIDER, H.; WOLF, P. G. A Classification for extant ferns. Taxon, Wien, v. 55, n. 3, p. 705-731, 2006.

STEEGE, H.; CORNELISSEN, J. H. C. Distribution and ecology of vascular epiphytes in lowland rain forest of Guyana. Biotropica, Washington, v. 21, p. 331-339, 1989.

TABARELLI, M.; LOPES, A. V. F.; PERES, C. Edge-effects drive tropical forest fragments towards an early-successional system. Biotropica, Lawrence, v. 40, p. 657-661, 2008.

TEIXEIRA, C. V. Florística e estrutura da borda de um fragmento florestal na cidade de São Paulo. Dissertação (Mestrado) - Universidade de São Paulo, São Paulo, 1998.

TROPICOS - Nomenclatural Data Base. Missouri Botanical Garden. Disponível em: <http://www.tropicos.org/home>. Acesso em: 25/07/2008.

VALDIVIA, P. E. Estudio botánico de la región del rio Uxpanapa, Vera Cruz. Biotropica, Washington, v. 4, p. 55-81, 1977.

VIANA, V. M. Biologia e manejo de fragmentos florestais. In: CONGRESSO FLORESTAL BRASILEIRO, 6., 1990, Campos dp Jordão. Anais, [São Paulo]: Sociedade Brasileira de Silvicultura : Sociedade de Engenheiros Florestais, 1990. p. 113-118.

VIEIRO DIAS, F. Estudo fitossociológico de epífitos vasculares no gradiente borda-interior de um remanescente de Floresta Ombrófila Mista. Monografia (Conclusão de Curso) - Universidade Regional Integrada do Alto Uruguai e das Missões, Erechim. 2006.

WAECHTER, J. L. Epífitos vasculares da mata paludosa do Faxinal, Torres, Rio Grande do Sul, Brasil. Iheringia, Série Botânica, Porto Alegre, v. 34, p. 39-49, 1986.

WAechter, J. L. O epifitismo vascular na Planície Costeira do Rio Grande do Sul. Tese de doutorado, Universidade Federal de São Carlos, São Carlos, 1992.

WAECHTER, J. L. Epifitismo vascular em uma floresta de restinga do Brasil subtropical. Ciência e Natura, Santa Maria, v. 20, p. 43-66, 1998.

WAECHTER, J. L. Epiphytic orchids in eastern subtropical South America. In: WORLD ORCHID CONFERENCE, 15., 1996, Rio de Janeiro. Proceedings... Turriers: Naturalia, 1996. p. 332-34. 
ZANARDI, C. Regeneração arbórea em uma área de transição entre Floresta Estacional e Floresta Ombrófila Mista na região sul do Brasil. Monografia (Conclusão de Curso) - Universidade Regional Integrada do Alto Uruguai e das Missões, Erechim, 2008.

ZIMMERMAN, K. J.; OLMSTED, I. C. Host tree utilization by vascular epiphytes in a seasonally inundated forest (tintal) in Mexico. Biotropica, Washington, v. 24, p. 402-407, 1992.

ZULOAGA, F. O.; MORRONE, O.; BELGRANO, M. J. (Org.). Catálogo de las plantas vasculares del Cono Sur (Argentina, Sur de Brasil, Chile, Paraguay y Uruguay). Saint. Louis: Missouri Botanical Garden, 2008. 